\title{
Optimalisasi produksi kerajinan Sulam Tekat melalui pengembangan kemampuan SDM di bidang disain Kelompok Usaha Bersama (KUB) Kuntum Bertuah di Kelurahan Harjosari Kecamatan Sukajadi, Pekanbaru
}

\author{
Elva Susianti*, Yusmar Palapa Wijaya, dan Tobi Arfan \\ Politeknik Caltex Riau \\ * elva@pcr.ac.id
}

\begin{abstract}
Abstrak. Kelurahan Harjosari Kecamatan Sukajadi merupakan daerah yang berada disekitar pusat pemerintahan daerah Pekanbaru. Di kelurahan ini, telah berdiri sebuah UKM yang bernama Tekat Tiga Dara sejak tahun 2009 dengan anggota pertama 2 (dua) orang dan berkembang sampai 10 (sepuluh) orang. UKM ini memproduksi dan menjual hasilhasil kerajinan tangan hasil karya anggotanya, antara lain kerajinan dari akrilik, sulam dan pelaminan. Untuk meningatkan pendapatan kelurga lingkungan sekitar UKM ini, bu Nurila sebagai pengelola membentuk dua Kelompok Usaha Bersama kerajinan (KUNTUM BERTUAH) dan makanan (MEKAR BERSEMI). KUB kerajinan beranggotakan 14 (empat belas) orang ibu-ibu rumah tangga yang tinggal di sekitar Jl. Dahlia gg. Jati Komplek kejaksaan. Hasil produksi utama dari KUB Kuntum Bertuah adalah Sulam Tekat. Sulam tekat adalah sulam khas melayu yang banyak di aplikasikan pada hiasan dinding, pelaminan, souvenir kegiatan kedaerahan maupun pernikahan. Bahan utama dari sulam tekat ini adalah kertas prada emas yang di tekatkan (di tempelkan) pada kain dasar (beludru, songket dll). Proses pengerjaannya di mulai dari membuat motif sulam pada kertas prada, menggunting motif, menempelkan dan menjahit pinggiran motif dengan benang emas. Proses yang paling sulit dan memakan waktu adalah menyulam dan membuat pola kertas. Membuat pola pada kertas dilakukan dengan menjiplak pola pada kertas prada, kemudian menggunting sesuai lekukan pada pola. Kedua proses ini membutuhkan kesabaran dan ketelitian yang tinggi. Jika salah potong, maka kertas prada yang harganya cukup mahal ini akan rusak dan tidak bisa digunakan. KUB ini sangat mengharapkan adanya alat yang bisa mencetak pola dan sekaligus memotongnya pada kertas prada. Untuk mengatasi masalah tersebut, anggota KUB akan dilatih menggunakan aplikasi komputer disain grafis sederhana yang biasa digunakan untuk mencetaknya pada mesin printer cutting stiker. Harapannya, dengan metode ini, pekerjaan pembuatan souvenir dengan motif apapun yang sama bisa di buat lebih singkat dan cepat. Diharapkan produksi KUB ini juga semakin meningkat sesuai dengan permintaan pasar.
\end{abstract}

Kata kunci: kertas prada, komputer disain grafis

\begin{abstract}
Harjosari Subdistrict, Sukajadi Sub-District is near from the central government of Pekanbaru. In this district, an UKM was established which was named Tekat Tiga Dara since 2009 with the first members of 2 (two) people and growi up to 10 (ten) people. This UKM produces and sells handicrafts produced by its members, including acrylic crafts, embroidery and aids. To remind the family income of the surrounding UKM, Nurila as the manager, formed two Craft Joint Business Groups (KUNTUM BERTUAH) and food (MEKAR BERSEMI). The KUB craft consists of 14 (fourteen) housewives who live around Jl. Dahlia gg. Jati. The main production from KUB Kuntum Bertuah is Sulam Tekat. Dense embroidery is a typical Malay embroidery that is widely applied to wall hangings, aisle, and souvenir for regional and wedding activities. The main ingredient of this dense embroidery is gold prada paper which is fixed (attached) to the base cloth (velvet, songket etc.). The process starts from making embroidery motifs on paper prada, cutting out motifs, pasting and sewing the edges of the motif with gold thread. The most difficult and time-consuming process is to embroider and make paper patterns. Making patterns on paper is done by tracing pattern on paper prada, then cut according to the curve of the pattern. Both of these processes requires high patience and precision. If it is wrongly cut, then this expensive material will be damaged and cannot be used. This KUB very hopeful for a tool that can print patterns and at the same time cut them on prada paper. To overcome this problem, KUB members will be trained to use simple graphic design computer applications commonly used to print it on cutting sticker printer machines. Hopefully, with this method, the work of making souvenirs with any of the same motifs can be made shorter and faster. It is expected that this KUB production will also increase according to market demand.
\end{abstract}

Keywords: paper prada, computer graphic design 
To cite this article: Susianti, S., Y. P. Wijaya, \& Tobi Arfan. 2019. Optimalisasi produksi kerajinan Sulam Tekat melalui pengembangan kemampuan SDM di bidang disain Kelompok Usaha Bersama (KUB) Kuntum Bertuah di Kelurahan Harjosari Kecamatan Sukajadi, Pekanbaru. Unri Conference Series: Community Engagement 1: 51-55. https://doi.org/10.31258/unricsce.1.51-55

(C) 2019 Authors

Peer-review under responsibility of the organizing committee of Seminar Nasional Pemberdayaan Masyarakat 2019

\section{PENDAHULUAN}

Politeknik Caltex Riau merupakan salah satu kampus mitra dari Dinas Perindustrian. Beberapa kebutuhan UMKM dibawah DISPERIN, diupayakan agar bisa dicarikan solusinya. Salah satu kendala dari UMKM binaan DISPERIN yaitu UKM Tekat Tiga Dara. Tekat Tiga Dara adalah salah satu pusat kerajikan Riau yang berlokasi di Komplek Kejaksaan, Jalan Jati, Kelurahan Harjosari, Kecamatan Sukajadi Kota Pekanbaru. UKM ini diketua oleh $\mathrm{Bu}$ Ila dan sudah banyak membantu ibu-ibu rumah tangga disekitarnya dalam meningkatkan perekonomian keluarganya. Produk yang dihasilkan adalah sulam tekat yang berbentuk souvenir, hiasan dinding, pelaminan, dll.

Kendala yang dihadapi oleh UKM ini adalah kesulitan dalam menggambar dan memotong kertas utama (Kertas Prada) dalam pembuatan sulam. Selama ini harus dilakukan beberapa proses yaitu menggambar pola d kertas, dan kemudian mengguntingnya. Model yang sangat sarat dengan lekuk, sangat menyulitkan saat di gambar ataupun di gunting. DISPERIN sudah mencoba memberi solusi dengan membuatkan stempel model sulaman, dan kemudian di cetak pada kertas prada. Tapi metode ini hanya bisa dilakukan untuk motif-motif kecil. Untuk motif besar tidak mungkin di lakukan. Dan kendala pengguntingan/pemotongan kertas sesuai motif, belum ada solusinya.

Setelah penulis mengunjungi mitra dan berdiskusi, salah satu anggota pengabdian melihat ada metode yang bisa dilakukan untuk membantu permasalahan UKM ini. Metode ini diharapkan bisa membantu permasalahan UKM dalam kesulitan menggambar dan menggunting pola. Sehingga produksi UKM ini bisa lebih banyak dan makin bervariatif.

\section{METODE PENERAPAN}

Untuk menyelesaikan kendala ini, penulis memberikan pengetahuan mengenai disain grafis. Sehingga setiap pola yang ada, sudah memiliki data digitalnya. Disain grafis yang diberikan adalah Corel Draw. Penulis sudah mempersiapkan panduan sederhana agar bisa meniru pola yang sudah ada dan kemudian bisa dikonversikan ke mesin cutting sticker. Dengan metode ini diharapkan proses menggambar cukup dilakukan satu kali, dan ketika dibutuhkan, maka tinggal di cutting menggunakan mesin. Dan hasilnya juga sama di setiap model pola.

Metode pelaksanaan PKM ini di mulai dari pembelian seperangkat komputer. Angota KUB Kuntum bertuah diberikan perlatihan tentang Corel Draw oleh Ketua dan anggota 1 tim PKM. Pelatihan dilakukan minimal 8 kali pertemuan kepada seluruh anggota KUB. Setiap pertemuan dilaksanakan selama 3 jam dan pada akhir pekan menyesuaikan jadwal tim PKM dan anggota KUB. Berikut rancangan pertemuan pelatihan corel draw (Hendratman, 2018):

1. Materi penggunaan Komputer dasar

2. Materi pengenalan aplikasi office

3. Materi pengenalan tools pada corel draw

4. Materi Membuat garis dan bentuk (kotak, segitiga, bulat, oval)

5. Materi Pembuatan pola 1 (sederhana)

6. Materi pembuatan pola 2

7. Materi modifikasi tahap 1

8. Materi teknik modifikasi pola tahap 2

Diluar jadwal ini, peserta tetap bisa konsultasi dengan pemateri.

\section{HASIL DAN KETERCAPAIAN HASIL}

Untuk membuat sebuah karya sulam tekat, di butuhkan beberapa proses. Disini akan dijelaskan proses pembuatan kipas souvenir. Proses pembuatan sebuah kipas di mulai dengan membuat pola pada kertas karton, dan kemudian di jiplak pada kertas prada emas/perak sesuai permintaan konsumen. Pola yang yang sudah di 
jiplak ini kemudian di potong mengikuti bentuk dan lekukan pola. Alat yang digunakan adalah pisau atau gunting berujung lancip. Gambar 1 memperlihatkan mal (pola) dan hasil jiplakan pada kertas prada.

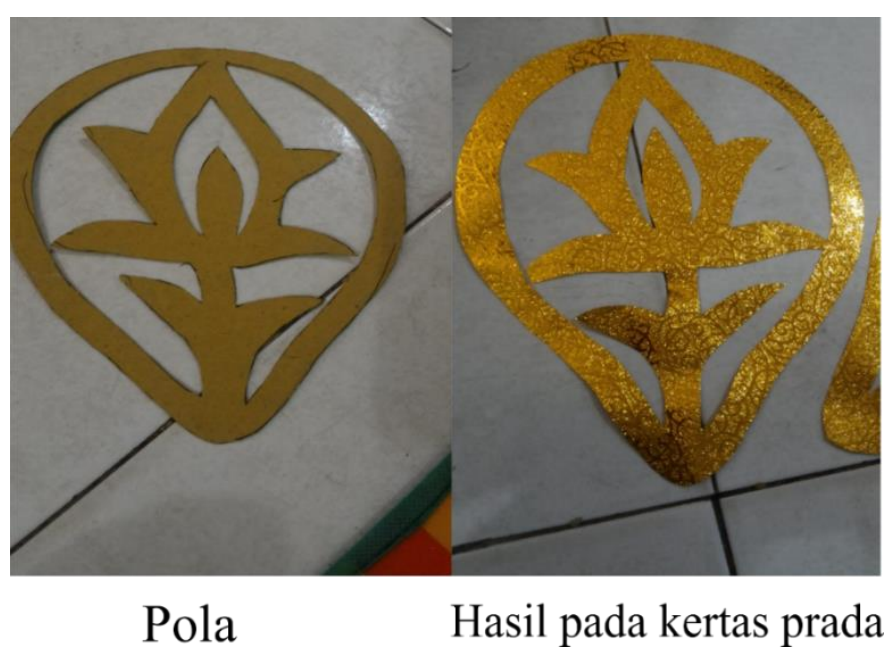

Gambar 1. Kertas Pola dan hasil jiplakan pada kertas prada

Pengerjaan jiplak hingga potong pola ukuran $10 \mathrm{~cm} \times 15 \mathrm{~cm}$ ini membutuhkan waktu lebih kurang 15 menit untuk pola pada gambar 1. Pesanan untuk kipas pada satu event bisa mencapai 200-500 pcs. Waktu pengerjaan untuk menjiplak dan memotong kertas sudah memakan waktu yang cukup lama. Sehingga UKM tidak bisa menerima pesanan dalam jumlah terlalu besar. Karna proses pengerjaan bukan hanya di jiplak dan gunting, masih ada proses selanjutnya yaitu menempel, menyulam dan finishing akhir. Gambar 2. adalah hasil akhir kipas.

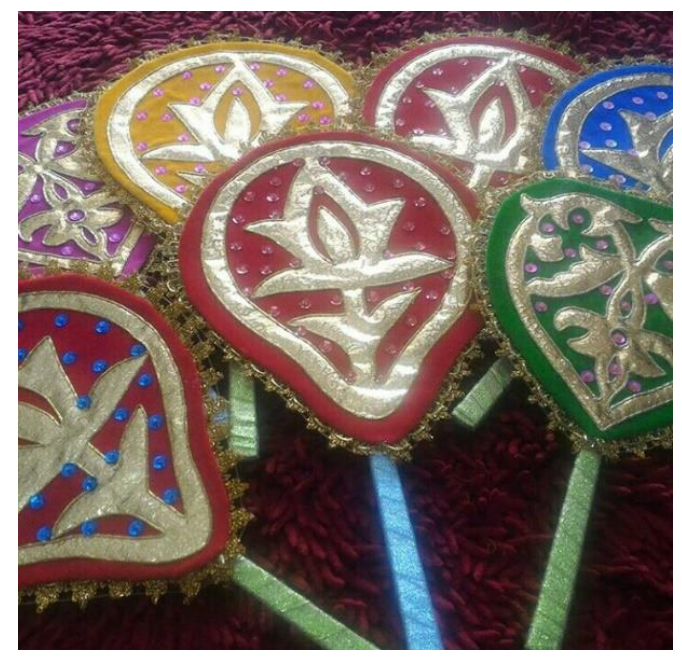

Gambar 2. Hasil akhir kipas souvenir

Motif yang di jual bukan hanya kipas. Beberapa produk yang selalu laris antara lain pajangan dinding berupa motif kaligrafi, kapal lancang kuning, pucuk rebung bahkan ada yang meminta disain khusu berupa logo komunitasnya. Proses pengerjaannya lebih membutuhkan waktu lagi karena harus mencetak pola terlebih dahulu pada kertas tebal, baru kemudian di cetak pada kertas prada dan di gunting. Lekukan lekukan yang banyak pada motif kaligrafi sangat menyulitkan dan membutuhkan waktu yang lama dalam pengerjaannya. Gambar 3 adalah contoh hasil sulam tekat dengan motif kaligrafi. 


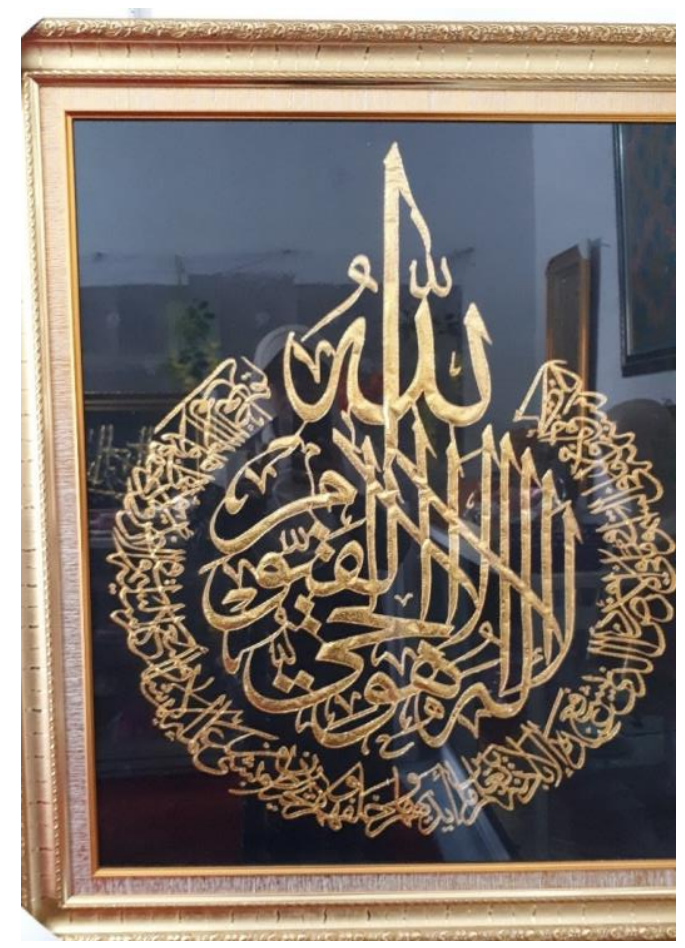

Gambar 3. Hasil sulam tekat motif kaligrafi

Proses menjiplak pola sudah pernah dicarikan solusi oleh Disperin pekanbaru. Yaitu dengan membuat stempel dan mencetaknya pada kertas prada. Akan tetapi, proses pengguntingan masih harus dilakukan manual. Gambar 4. memperlihatkan pola yang sudah di buatkan stempelnya.

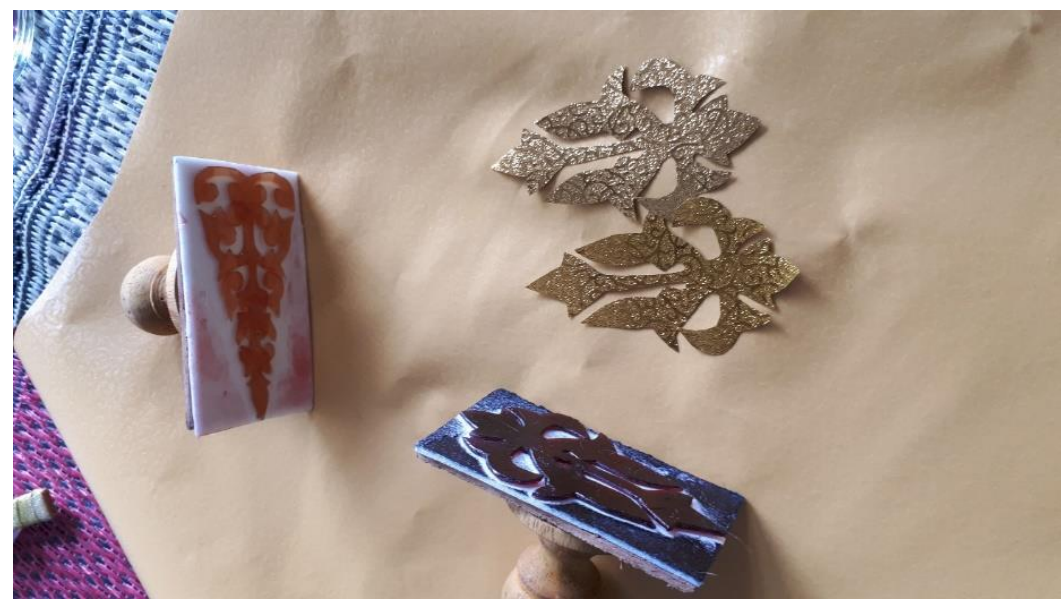

Gambar 4. Pola yang sudah di buatkan stempel

Pada gambar 4 dapat dilihat bahwa pola yang bisa di buatkan stempelnya hanya bisa untuk motif-motif kecil. Untuk motif besar tetap harus di jiplak manual pada kertas prada. Sehingga masalah utama dari membuat pola kertas prada belum terpecahkan secara keseluruhan.

Komputer grafis tidak bisa kita abaikan di era digital ini. Bukan hanya di industri, UKM pun harus bisa bersaing di era digital ini. Pekerjaan yang dilakukan secara manual, sudah harus dicarikan solusi agar bisa lebih efisien di waktu. Sehingga kualitas dan kuantitas karya bisa semakin meningkat.

Kesulitan dalam memberikan pengetahuan komputer grafis ini adalah, minimnya pengetahuan anggota UKM mengenai komputer. Karena anggotanya adalah ibu rumah tangga yang berusia antara 35-50 tahun. Sehingga tim PKM memfokuskan materi kepada anak dari anggota UKM ini. 


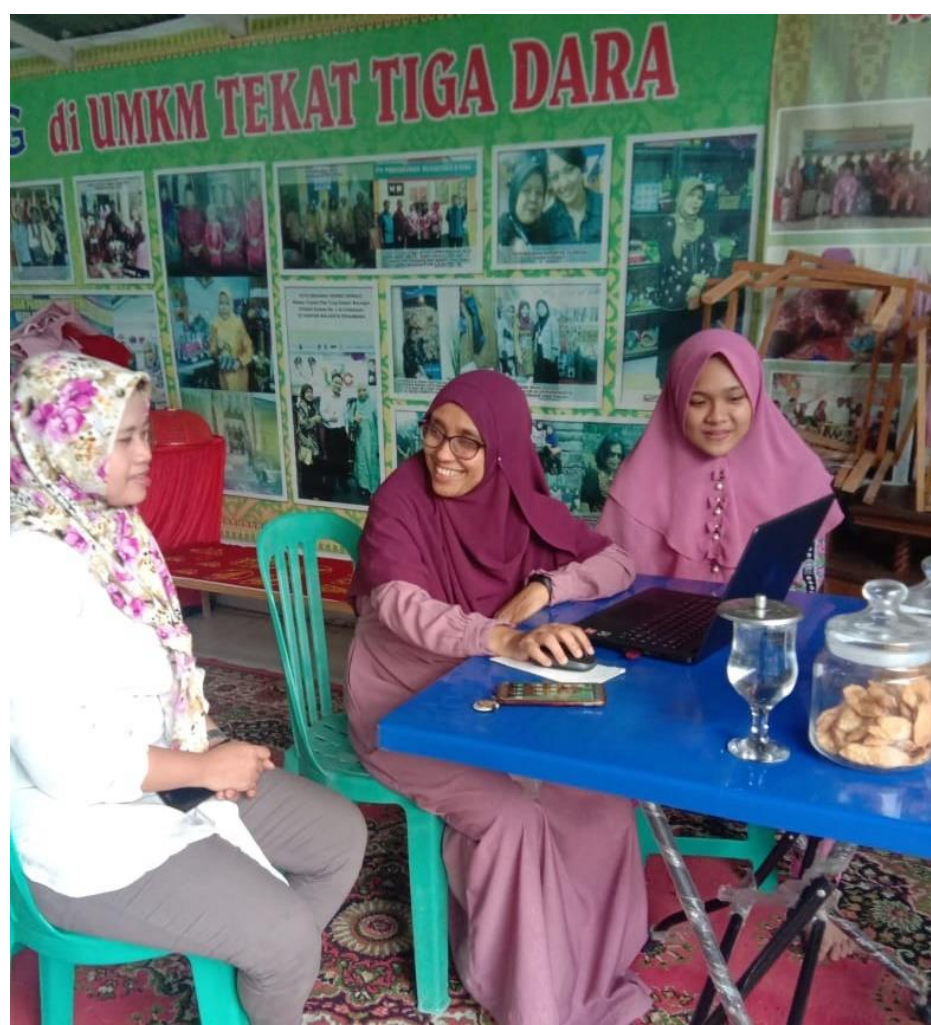

Gambar 5. Kegiatan Pelatihan

Kegiatan pelatihan ini masih akan berlanjut. Dan outputnya diharapkan ada dua atau tiga peserta yang bisa menguasai disain grafis ini dan bisa menghasilkan karya yang lebih bervariatif.

\section{KESIMPULAN}

Pengabdian Masyarakat ini sedang berjalan dan baru mencapai target $40 \%$ dari keseluruhan yang diharapkan. Masih dibutuhkan waktu yang lebih banyak agar UKM bisa menguasai disain grafis ini dengan lebih baik. Dari UKM, merasa sangat terbantu dengan solusi yang diberikan penulis. Dan mengharapkan ada pengembangan lainnya terkait kualitas karya yang dihasilkan yaitu kebutuhan mesin bordir otomatis. Karena beberapa pesanan dari konsumen meminta ada tulisan khusus yang di tampilkan di karya mereka. Saat ini jika ada permintaan tersebut, terpaksa di tolak karena ketidak sanggupan anggota UKM untuk mengerjakannya. yang sangat sarat dengan lekuk, sangat menyulitkan saat di gambar ataupun di gunting.

\section{UCAPAN TERIMA KASIH}

Terimakasih penulis ucapkan kepada Ristek Dikti yang sudah memberikan bantuan dana pada program Hibah Pengabdian Masyarakat 2019. Terimakasih juga di berikan kepada Kampus Politeknik Caltex Riau yang sudah memfasilitasi pengabdian masyarakat ini, dan mahasiswiku Ririn Ranto wati yang sudah membantu proses pengerjaan proposal.

\section{DAFTAR PUSTAKA}

Hendi, H. 2018. The Magic of Corel Draw. Informatika. 